\title{
有機溶剂中でのポリエチレンテレフタレート への分散染料の拡散速度*
}

\author{
京都工芸㵶維大学工芸学部橋 本勇 \\ THE RATE OF DIFFUSION OF DISPERSE DYE ON \\ POLY(ETHYLENE TEREPHTHALATE) IN ORGANIC SOLVENT DYEING
}

By Isamu Hashimoto

(Kyoto University of Industrial Arts and Textile Fibers, Matsugasaki, Sakyo-ku, Kyoto, Japan)

The diffusion coefficients of C.I. Disperse Red 17 in poly(ethylene terephthalate) were measured in various solvents by the film-roll method. The effect, of temperature on the diffusion coefficient was discussed from a viewpoint of Williams-Landel-Ferry equation, and the following results were obtained.

(1) The temperature dependence of the diffusion coefficients of C.I. Disperse Red 17 in organic solvent dyeing obey the Williams-Landel-Ferry equation,

$$
\log a_{T}=-\frac{3.94\left(T-T_{s}\right)}{26.0+T-T_{s}}
$$

where $a_{T}$ is shift factor, and $T_{s}$ the standard temperature.

(2) The effect of solvents on the diffusion coefficient are explained in terms of the lowering of $T_{s}$ due to the decrease of the glass transition temperature of the polyester by absorbing the relevant solvent.

(Received November 1, 1976)

\section{1. 緒言}

有機溶剤中でのポリェチレンテレフタレートの染色挙 動について壮，取近，多くの報告がある。すなわち有機

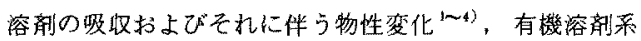
での分散染料の平衡染着举動 ${ }^{4 \sim b)}$ および動力学的举動 などの研究がある。

動力学的举動の大半はパータロルエチレン系での研究 であり ${ }^{8,7,8)}$, それ以外の溶郕として 1 -ブタノールなど

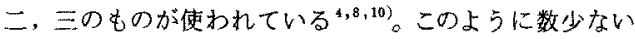
溶剂系加らの知見のみでは，動力学的举動に及ぼす溶媒 の影響は分らない。

そこで本報では 11 種の溶剂系での拡散挙動を広い温 度範囲に亘って検討した結果，捘散係数の温度依存性法， Williams, Landel, Ferryの式(以下WLF式とする) に従い，同時に，浴剤の違いによる払散係数の相違は溶 敦による基準温度の相違として説明できる。更に水をも “この報文を「溶凨染色に関する研究(第8 報)」「Studies on Solvent Dyeing (part 8)」とする。
含めたすべての溶剂采での拡散は一つのWLF式で統一 できることがわかった。

\section{2. 実験方法}

\section{1 試 料}

試料としてはポりエチレンテレフタレート・フィルム (三菱樹脂製，厚さ $16 \mu$, 密度 1.403 ) を使用した。フ イルムは使用前にエーテルで洗海し，夾雅物を除去した 後、風乾し、デシタータ中に保存して使用した。

染料 (C.I.Disperse Red 17の精製品)，薬品は削報 と同様である ${ }^{12)}$ 。

\section{2 染色条件}

染任はトリアセテートの場合と同槏に巻厤法で行ら また染色条件も前報と同じである ${ }^{12)}$ 。搪散俰数は巻篔法 に関する関戸，松井の方法に従って算出した ${ }^{18)}$ 。

\section{3 密 度}

溶剂処理前後の密度变化を、トリアセテートの場合と

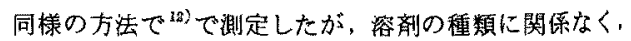
染色条件の範曲で注明確な变化注認められない。 


\section{4 収樎高}

前報 ${ }^{14)}$ と同様にして測定した。

\section{3. 結果と考察}

\section{1 拡散係数の温度依存性とWL F 式の適用} 各種容刘系での分散染料の抾散係数之温度との関係は 因 1 括よび図 2 のよらに曲線関係を示す。そして曲線の 形加ら厸散係数の温度低存性はWLF 式で表わされると 考えられる。

一般に，WLF式の基準温度として収樎開始温度が使 われているが ${ }^{15,16)}$ ，その理由は收縮開始温度がガラス転 移温度に対代することによっている ${ }^{17,18) 。 ~}$

いま、本，0ージクロルベンゼンおよびェチルベンゼ ン中での収縮開始温度は図 3 からそれぞれ，88，64 お

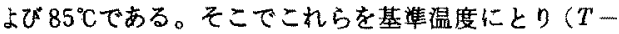
$\left.T_{S}\right) / \log a_{T}$ と $T-T_{S}$ とをプロットすると図 4 が得られ， その直線の勾配拉よび切片から式（1）のWLF式によ二 て定数 $C_{1}$ および $C_{2}$ が算出でき，それぞれ 3.94 および 26.0 である。

$$
\log a_{T}=-\frac{C_{1}\left(T-T_{S}\right)}{C_{3}+T-T_{S}}
$$

ここで $a_{T}$ は移動因子で，基準温度 $T_{S}$ おび温度 $T$ に括

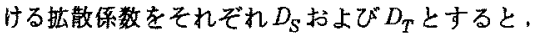

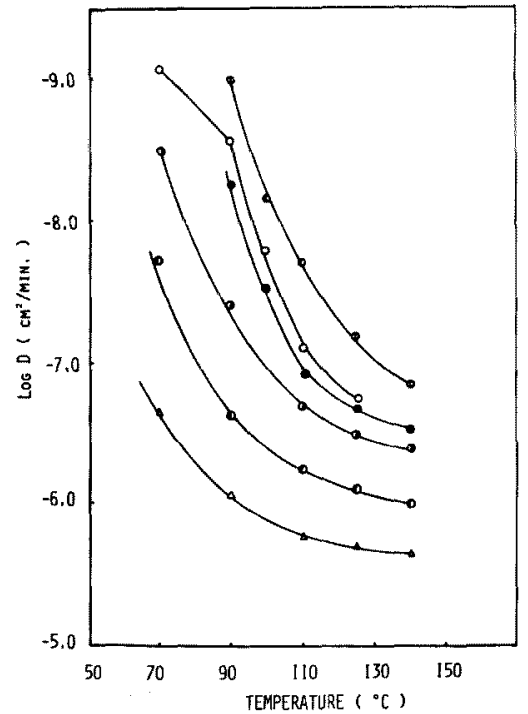

Fig. 1 Effect of temperature on diffusion coefficient for poly(ethylene terephthalate)

Water (D), 1-Pentanol (O),

Perchloroethylene (O),

o-Dichlorobenzene (O),

Chlorobenzene ( $(0)$, Nitrobenzene $(\Delta)$.

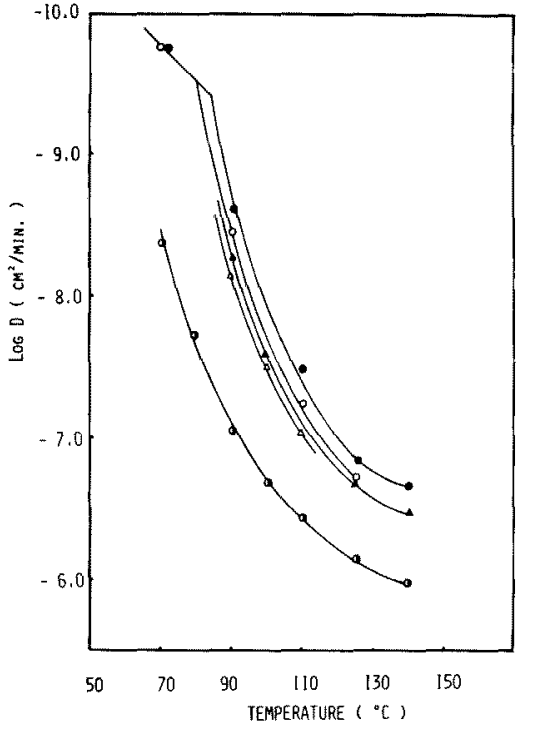

Fig. 2 Effect of temperature on diffusion coefficient for poly(ethylene terephthalate).

Ethylbenzene (O), m-Xylene (O),

Butylacetate $(\Delta)$, Methyl isobutyl ketone $(\Delta)$ $\alpha$-Methyl naphthalene (O)

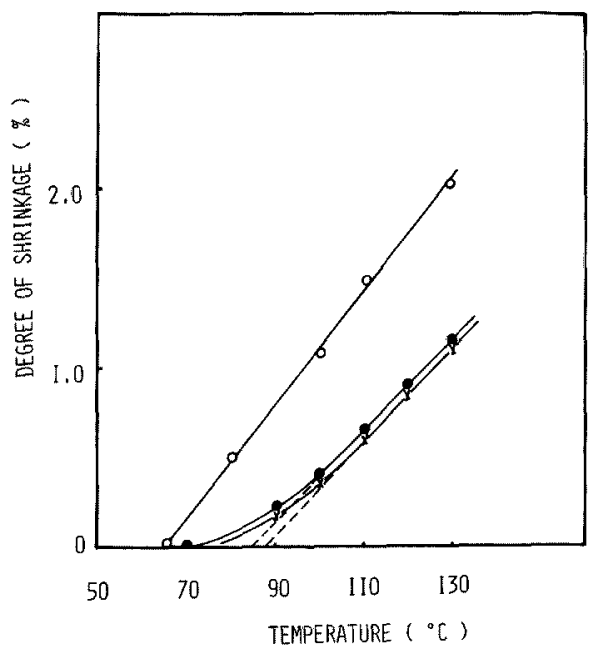

Fig. 3 Effect of temperature on shrinkage of poly(ethylene terephthalate).

Water $(x)$, o-Dichlorobenzene $(0)$, Ethylbenzene (๑). 


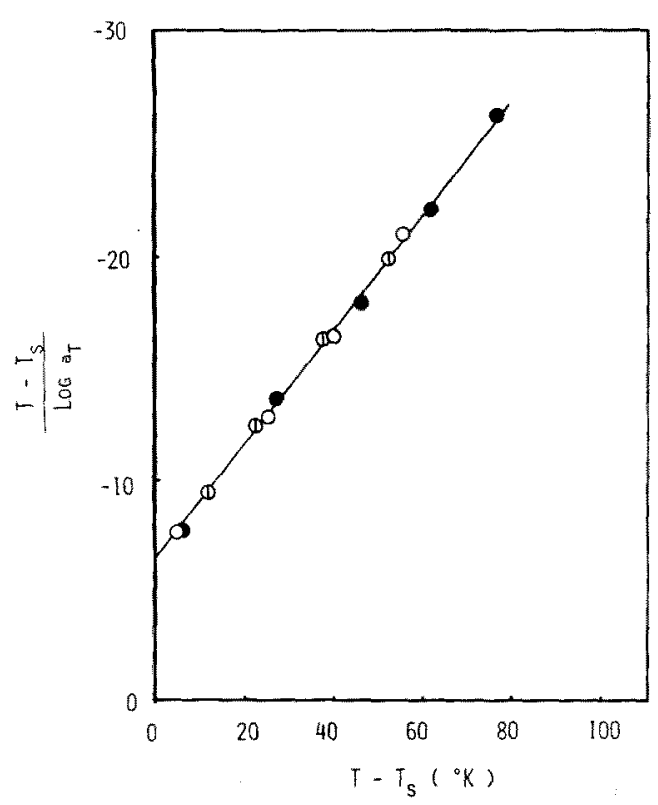

Fig. 4 Plot of $\left(T-T_{s}\right) / \log a_{T}$ ys $T-T_{s}$ for poly(ethylene terephthalate).

Ethylbenzene (O), Water (D),

o-Dichlorobenzene

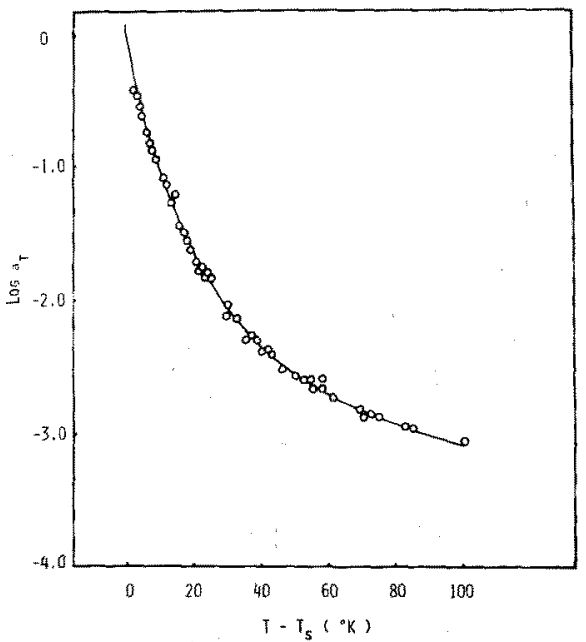

Fig. $5 \log a_{T}$ plotted against $T-T_{S}$ for poly(ethylene terephthalate).

Solid curve, calculated from equation 1.

$$
a_{T}=\frac{D_{S}}{D_{r}}
$$

で与えられる。

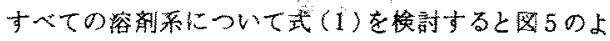

うであり，园中の実線は式（1）からの計算值であり，ま た各点はこの曲線に適合するように基準温度を選んでブ

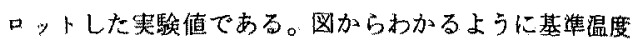

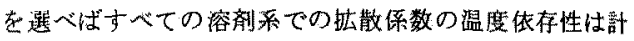
算值に一致する。

各種溶威の基準温度㹥1表1のうである。そしてこの

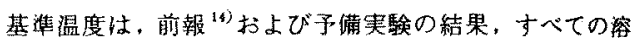

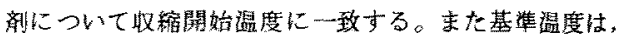

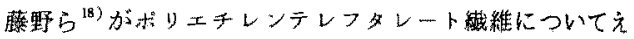

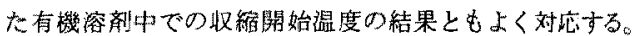

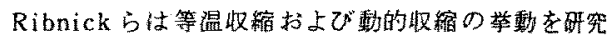

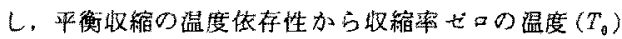
を求め， $T_{0}$ ががラス転移温度であると考えている゙す。

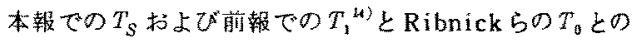

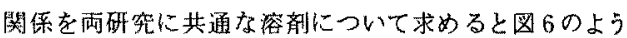
であり，使用試料の違いにも拘らずこれらの間に悢好

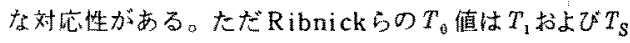
に比較してかなり低温である。

本来，高分子物質のガラ又転移温度はせダィントの搪 散速度が測定のタイムスケールと问程偠になる温度であ るため,タイムスケールの相違はガラス転移温度を変化

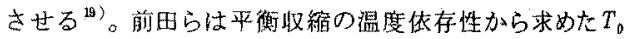

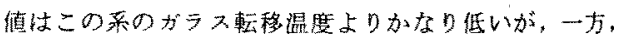

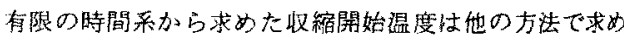
たガラス転移温度にほぼ一致するとして㧍り，その理由 をガラス転移温度の速度諭的因子，つまりタイムスター

Table 1. Standard temperature $\left(T_{s}\right)$, diffusion coefficient at $T_{s}\left(D_{s}\right)$ and activation energy at $100^{\circ} \mathrm{C}\left(E_{d}\right)$ on poly(ethylene terephthalate).

\begin{tabular}{lccc}
\hline \multicolumn{1}{c}{ Solvent } & $\begin{array}{c}T_{s} \\
\left({ }^{\circ} \mathrm{C}\right)\end{array}$ & $\begin{array}{c}\log D_{s} \\
\left(\mathrm{~cm}^{2} / \mathrm{min} .\right)\end{array}$ & $\begin{array}{c}E_{d} \\
(\mathrm{kcal} / \mathrm{mol})\end{array}$ \\
\hline Water & 88 & -9.47 & 44.5 \\
1-Pentanol & 83 & -9.30 & 34.8 \\
Chlorobenzene & 54 & -9.10 & 12.4 \\
o-Dichlorobenzene & 64 & -9.30 & 16.7 \\
Perchloroethylene & 81 & -9.10 & 31.8 \\
m-Xylene & 86 & -8.90 & 40.2 \\
Ethylbenzene & 85 & -9.25 & 38.3 \\
Nitrobenzene & 40 & -8.80 & 8.7 \\
n-Butyl acetate & 82 & -9.00 & 33.2 \\
Methyl isobutyl ketone & 83 & -9.00 & 34.8 \\
$\alpha$-Methyl naphthalene & 67 & -8.85 & 18.5 \\
\hline
\end{tabular}




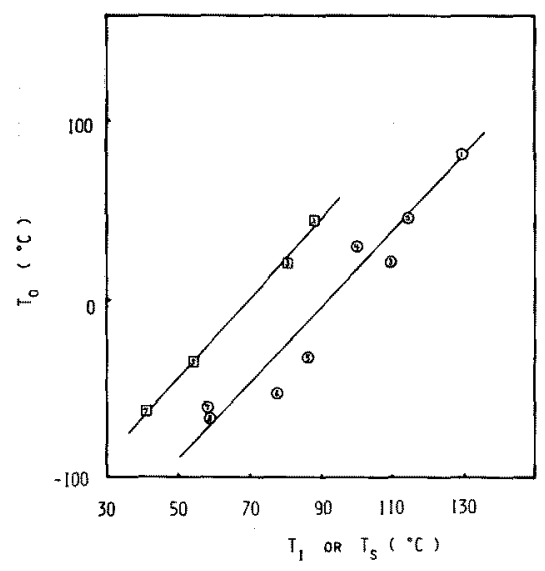

Fig. 6 Relation between $T_{1}$ or $T_{s}$ and $T_{0}$ by Ribnick et al $^{2)}$.

$T_{0}$ vs $T_{1}(\mathrm{O}), T_{0}$ vs $T_{s}(\mathrm{D})$.

1. Dry, 2. Water, 3. Perchloroethylene,

4. 1-Butanol, 5. Chlorobenzene,

6. Nitromethan, 7. Nitrobenzene,

8. 1,4Dioxane.

ルに求めている ${ }^{20)}$ 。前田らの考え方は $T_{0}$ と $T_{1}$ 抢よび $T_{\mathrm{S}}$ の相違にも適用できる。

染色時間を一定にした場合，染着率之温度との間には $\mathrm{S}$ 字型曲線がえられ ${ }^{15,21)}$ ，その変曲点は収縮開始温度に 非常に近い ${ }^{15,22)}$ 。金丸はこの变曲点が高分子の $\alpha^{\prime}$ 分散域 に現れ，また搪散転移温度 $\left(T_{d}\right)$ に近いことから，㹡散の ための孔形成のセグィント連動に最も関連の深い温度域 としている ${ }^{1,23,24)}$ 。またThompson-Wood は分散域 $\alpha^{\prime}$ およびきはそれぞれ芳香族核部分およびェチレンオキシ 卜結合の回転的应散運動に対応して現孔るとしている゙29 これらのことから容剤眼着によって分散域 $\alpha^{\prime}$ を低温に移 行させ、その結果，これと関連のある温度，たとえ致基 淮温度, 收稚開始温度 ${ }^{14)}$, 拡散転移温度 ${ }^{1)}$ などを低温側 に移動させると考えられる。

また図1拉よび図2から1ーペンタノ一ル，エチルベ ンゼンおよびmーキンレンなどを搈媒とした時の桩散係 数は基準㶅度付近で大きく变化する。これと類似の現象 はトリアセテートについてもみられる ${ }^{12)}$ 。そしてこの変 曲点が基準温度で現机る理由は上記の金丸の理論によ。

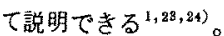

基準温度の低下に伴い，式(1)の関係から抬散係数の 增加が考えられる。すなわち基準温度と拡散俰数との間 には図 7 の関係がある。基準温度での抬散係数は表 1 に 示すように， $\log D_{\mathrm{S}}$ がー9.1土0.3であり，いま $\log D_{S}$ を-9.1として式(1)から $T_{S}$ と $\log D_{T}$ との関俰を示すと 图 7 の実線のように実験結果とよく一致する。

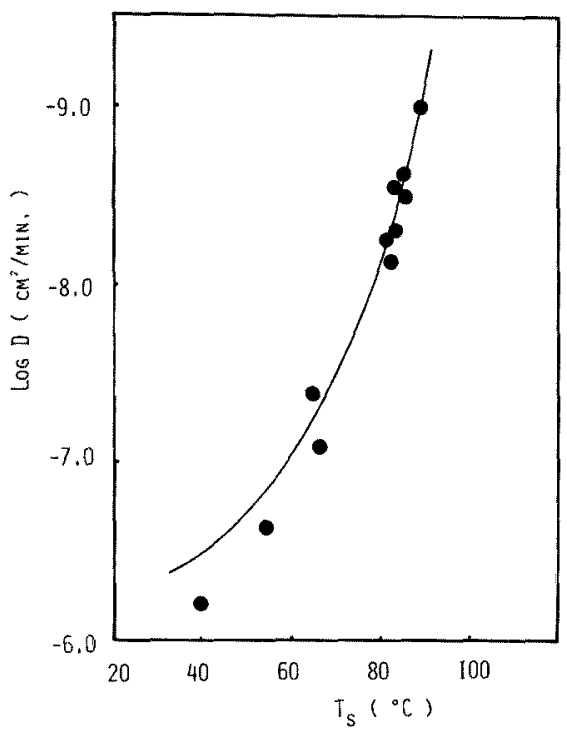

Fig. 7 Relation between diffusion coefficient at $90^{\circ} \mathrm{C}$ and standard temperature for poly(ethylene terephthalate).

Solid curve, calculated curve.

抬散保数の温度依存性がWLF式に従う境合，抎散活 性化エネルギーは $T_{S}$ と $T$ とで变化する"1) $100^{\circ} \mathrm{C}$ での坛 散活性化エネルギーは表1のようであり，TS 低下に 伴い大きく低下することがわかる。

\section{2 本系での分散染料の拡散係数に対する WLF 式の適用}

ポりエチレンテレフタレートへの分散染料の摭散につ いて，水系执よびキ+リヤ一染色系にWLF式が適用て

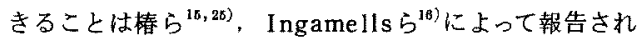
ている。また酒井らは分散染料の昇華抁散にWLF式を 適用している ${ }^{20)}$

Pattersonらは瀻維㮱造の相違する 3 種の瀻維につい て桩散係数を測定している ${ }^{27)}$ 。彼等の結果加ら，抎散保 数と温度との関係は，同一染料については，3 種の緎維 相互に類败した曲線を示す。そこでNータイプを基隼に

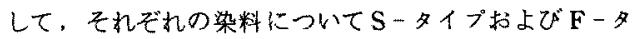
イプの曲線を温度軸に沿って低温側に平行移動させ，重 ね合せた合成曲線が図8である。潞度移動量はC.I.Dis一 perse Red 1 ではS-タイブについて $6^{\circ} \mathrm{C}$ ，またC.I. Disperse Red 15 ではSータイプで $6^{\circ} \mathrm{C}, \mathrm{F}$-タイブで $4^{\circ} \mathrm{C}$ である。

図 8 の合成曲線はをの型加らWLF式((1)式)で表わ されると考えられる。そしてこの合成曲線のデータから WLF 式定数 $C_{1}$ 㧍よび $C_{2}$ を决めるにはかなりの任意性が 


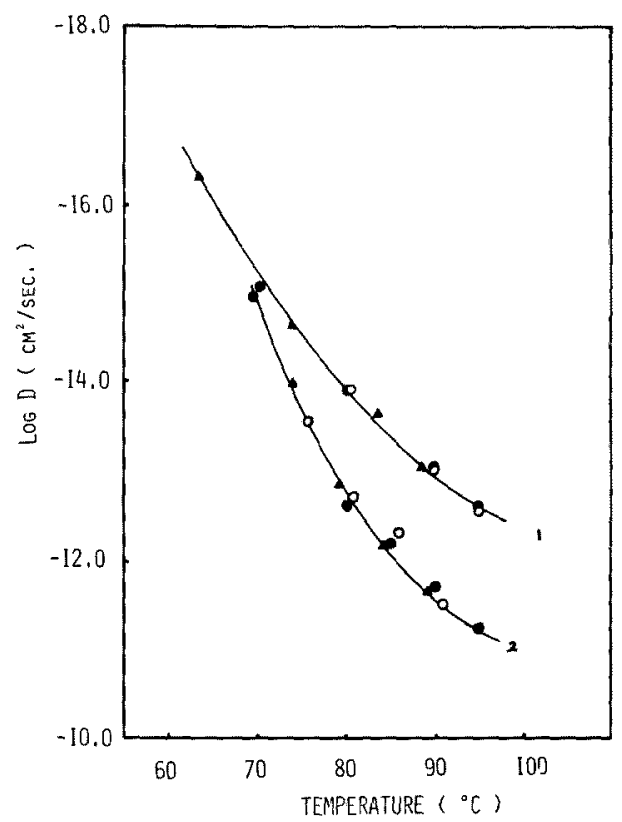

Fig. 8 Composite curves of $\log D$-temperature relations obtained by shifting the curves cited along the temperature axis. Data by Patterson and coworkers ${ }^{23)}$,

Curve 1: C.I. Disperse Red 1,

Curve 2: C.I. Disperse Red 15.

N-type fibre (@), F-type fibre (O),

Staple fibre $(\Delta)$.

認められている ${ }^{26)}$ 。特に基準温度の選定はガラ入転移温 度などの特性値が与えられている場合以外では任意性が あり、また基準温度を変えた場合のWLF式定数の換算 も容易である ${ }^{26)}$ 。そこで図 8 において基準温度を $70^{\circ} \mathrm{C}$ に仮定すれば，(1)式のC 1 扔よびC Red 1 では6.45 扔よび38.0、またC. I.Disperse Red 15 では 8.0 および 28.0 となる。

$\mathrm{F}$ ータイプはNータイブを延伸した䋳維であり，S一 タイプはNータイプを $140^{\circ} \mathrm{C} て ゙$ 熱セットした短織維であ る。このように履歴の相違する瀻維種に，曲線の重祇合 せを行い，WLF 式を適用することは椿ら，酒井らによ っても報告さ机ている ${ }^{15,26,26)}$ 。酒井らは熱膺歴の差によ る結晶化度のちがいの影響を $\log D$ 軸での移動量として 表わしている ${ }^{26)}$

森田らは䄉維試料を一定にして 5 種の染料について詓 散係数の温度依存性を詳細に梌討している ${ }^{23) 。 い ま ハ ゚ ラ ~}$ ニトロフニリンを基準にして他の 4 種の染料の曲線を温 度軸に沿って低温側に平行移動して合成曲線を作ると図 9 がえられる。この場合の移動量はパラアミノアッバン

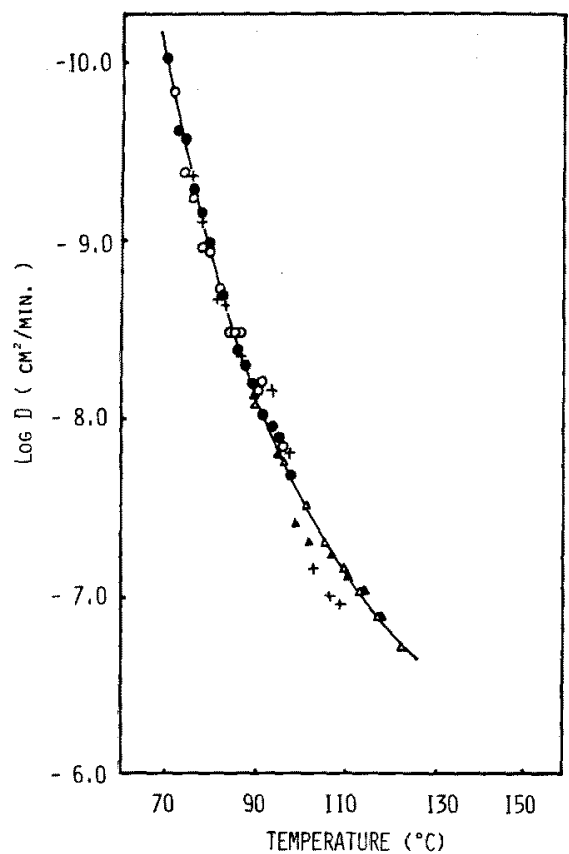

Fig. 9 Composite curve of $\log D$ - temperature relation obtained by shifting curves cited along the temperature axis. Data by Morita et al ${ }^{25)}$.

p-Nitroaniline $(0)$, p-Aminoazobenzene $(0)$, C.I. Disperse Violet $1(+)$,

C.I. Disperse Violet $8(\Delta)$,

C.I. Disperse Orange $13(\Delta)$.

ぜンで $13^{\circ} \mathrm{C}, \mathrm{C}$ I Disperse Violet 1 で $23^{\circ} \mathrm{C}$, C.I. Disperse Violet 8 で $30^{\circ} \mathrm{C}$. C.I. Disperse Orange 13 で $33^{\circ} \mathrm{C}$ であり，移動量怯染料の分子量の增加に伴。 て直線的に增加する。移動量々染料分子量との直線関保 は酒井らによって年華厸散の場合に漶力られている

菻田らの研究では，数種の転移点が指摘されている が28)，この転移点が存在するとしても、転移点を含めて 重祇合せが可能である。しかしC. I.Disperse Violet 1 任 $115.8^{\circ} \mathrm{C} よ り$ 高温側で，合成曲線から大きくずれる。 图 90 合成曲線は，基準温度を $70^{\circ} \mathrm{C}$ に仮定すれば， $C_{1} 5.88, C_{2} 41.2$ WLF 式で表せる。

伊藤らの研究でも，界華拡散の祭，数種の転移点が認 められているが29)，椿ら ${ }^{15)}$ 抢よび酒井ら ${ }^{26)}$ は付藤らの結 果について転移点を含めて曲線の重ね合せが可能であり， 合成曲線はWLF式に従らとしている。

\section{4. 結語}

ポりェチレンテレフタレートへの分散染料の牊につ いて，搪散係数に及ぼす温度および溶剂の影響を検討し 
た。その結果，次のことがわかった。

（1）払散俰数の温度依存性はWLF式で表わされ，C. I. Disperse Red 17 では $C_{1} 3.94 ， C_{2} 26.0$ がえられた。 また溶凧に関保なく $C_{1} 、 C_{2}$ は一定である。

（2）容㶡の種類による抬散係数の变化は，溶剂による 状りエチレンテレフタレートの基準温度の変化によって 起る。基準温度の低下に伴い，任意の温度での桩散係数 は増加し，払散活性化エネルギーは低下する。

付記：本研究に際し，ご懇もなご指導ならびにご助言 をいただいた大阪府立大学，黒不宣产教授ならびに京都 女子大学，片山明教授に深楅いたします。

\section{文献}

1) K. Kanamaru, M. Sugiura; Koll-Z. Z. Polym., 178, 1 (1961); 194, 110 (1964)

2) A.S. Ribnick, H.D. Weigmann, L. Rebenfeld; Text. Res. J., 42, 720 (1972), 43, 176 (1973); A.S. Ribnick, H. D. Weigmann; Text. Res. J., 43, 316 (1973), 44, 165 (1974); B. H. Knox, H. D. Weigmann, M. G. Scott; Text. Res. J., 45, 203 (1975); H. D. Weigmann, M. G. Scott; Text. Res. J., 45, 554 (1975)

3) 羽賀，石橋；䄉学誌，29，T251，T489（1973）

4）清水，木村; 学振第 120 委員会年報，23，81 $(1971), 24,102(1972), 25,153(1973)$

5) 鶴岡，小島; 緎学誌, 24, 35（1968）

6) K.V. Datye, S.C. Pitkar, U.M. Purao; Textilveredlung, 6, 593 (1971)

7) 片山，北野，黑木; 瀻学誌，28，302(1972)
8) 小島；工化, 70, 183 (1967)

9) Z. Morita, R. Kobayashi, K. Uchimura, H. Motomura; J. Appl. Polym. Sci., 19, 1095 (1975)

10) W. S. Perkins, D. M. Hall; Text. Res. J., 43, 115 (1975)

$11)$ M. L. Williams, R. F. Landel, J. D. Ferry; $J$. Amer. Chem. Soc., 77, 3701 (1955)

12) 橋本; 繊学誌, 33, T $123(1977)$

13) 関戸；学振第 120 委員会年次報告, 12, 195(1960)

14) 橋本; 瀻機誌, 28, T 126 (1975)

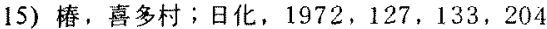

16) W. Ingamells, R.H. Peters, S.R. Thornton; J. Appl. Polym. Sci, 17, 3733 (1973)

17) 藤野，藤本，江藤；瀻機誌，14，291 (1961)

18) 藤野, 黒田, 藤本; 絨学誌, 21，573(1965)

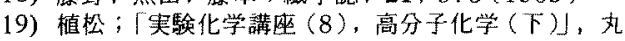
善，p. $83 \sim 115$ (1957)

20) 前田, 寺井, 河合; 工化, 63，1520（1960）

21) B. Kramrisch; J. Soc. Dyers Colour., 73, 85 (1957)

22) A.B. Thompson, D.W. Woods; Trans. Faraday Soc., $52,1383(1956)$

23）金丸；工化，63，1503(1960)

24) 金丸; ;高分子物性工学」, 地人畫館, p. $283 \sim 320$ (1968)

25）喜多村，小林；日化，1972，2127（1972)；喜多 村, 吉田, 椿; 日化, 1972，2219(1972)

26) 酒井，宮城，石川; 瀻学誌，30，T571(1974), 31, T 91 (1975)

27) D. Patterson, R. P. Sheldon; Trans. Faraday. Soc., $55,1254(1959)$

28) 森由, 小山, 飯扁; 日化, 1972, 1522(1972)

$29)$ I. Ito, S. Okajima, F. Shibata; J. Appl. Polym. Sci., 14,551 (1970) 